\title{
Developing a new specialty - sport and exercise medicine in the UK
}

This article was published in the following Dove Press journal:

Open Access Journal of Sports Medicine

3 March 2010

Number of times this article has been viewed

\section{Michael Cullen}

Department of Sport and Exercise Medicine, Musgrave Park Hospital, Belfast, UK
Correspondence: Michael Cullen Department of Sport and Exercise Medicine, Musgrave Park Hospital, 20 Stockman's Lane, Belfast BT9 7JB, UK Tel +4428906 6950l ext 2566 Email michael.cullen@belfasttrust.hscni.net
Abstract: Sports physicians have existed since ancient times. However as a recognised specialty, sports medicine is a relatively new discipline and even today very few countries have formal postgraduate training programmes which allow doctors to pursue a career in this discipline. This paper outlines the development of sport and exercise medicine in the United Kingdom, describing the journey leading to specialty recognition in 2005 and the progress being made towards establishing it as an integral component of the National Health Service in the 21 st century.

Keywords: sport and exercise medicine, specialty development, curriculum and training programmes

\section{Introduction}

Sports medicine can trace its origins back five thousand years to East Asia and the Taoist priests and monks in China who advised healing exercises to cure illness and achieve immortality of the soul. Hippocrates ( 460 - ca 377 BC) was initially sceptical of the healing power of exercise but he was eventually won over, writing in his paper On diet that "in order to remain healthy, the entire day should be devoted exclusively to ways and means of increasing one's strength and staying healthy, and the best way to do so is through physical exercise."

Plato (427-347 BC) referred to medicine as a sister art to physical exercise. This philosophy was further developed by Galen (131-201 AD) who advocated that the doctor should prescribe exercise. Indeed Galen, who was responsible for looking after the health of gladiators in the second century AD could rightly claim to be the first team doctor.

In Britain, the British Olympic Association appointed an official medical officer for the first time in 1928. The British Association of Sports Medicine (BASM) was formed in 1953, changing its name to the British Association of Sport and Exercise Medicine (BASEM) in 1998 in recognition of the increasing understanding of the role of physical activity in promoting and maintaining good health. This proved to be an extremely important step towards recognition of the specialty in the UK as government strategy looked to address the alarming tide of disease and morbidity associated with an increasingly sedentary population. BASEM continues to flourish today, publishing (with BMJ Publishing Group) the British Journal of Sports Medicine on a monthly basis and providing regular educational meetings for doctors and allied health professionals.

In February 2005, the UK government announced that sport and exercise medicine (SEM) would be developed as a new speciality of medicine. This article is intended 
to provide the reader with an understanding of the process involved in the development of the new speciality of SEM, its scope and curriculum.

\section{Sport and exercise medicine}

The Commons Health Select Committee issued a report, in March 2001, concluding that the government was not adequately promoting the health benefits of sport. Additionally, it stated that the Department for Culture, Media and Sport (DCMS) should develop closer links with the Department of Health (DH). Following this, the then Minister for Sport, Richard Caborn MP, co-chaired a SEM forum in March 2003 to consider the way forward for postgraduate education in SEM. A workgroup was established with members of the medical profession supported by UK Sport, DCMS and DH and tasked to develop a four-year higher specialty training program for doctors wishing to specialize in SEM. This workgroup subsequently produced the application for specialty recognition that was submitted to the government in January 2004. This then underwent a consultation process involving a wide range of stakeholders between August and November 2004 and culminated in the ministerial announcement in February 2005 that SEM was to be developed as a discrete medical speciality. Parliament amended the Specialist Medical Order in September 2005 and in October of that year the Academy of Medical Royal Colleges agreed the formation of the UK Faculty of Sport and Exercise Medicine under the auspices of the Royal College of Physicians of London and the Royal College of Surgeons of Edinburgh.

The specialty development was timely and complementary to several government strategy papers. Game plan ${ }^{1}$ (the strategy for delivering the government's sport and physical activity objectives) was published in December 2002 from the Prime Minister's Strategy Unit and DCMS. This spoke of the need for a national strategy for increasing levels of physical activity across the nation and was complementary to the government White Paper Choosing health (2004) ${ }^{2}$ and, more recently, Be active, be healthy (2009), ${ }^{3}$ which outlines the plan for the UK to become a more physically active nation. In addition to these strategy documents, Lord Darzi has published High quality care for all: NHS next stage review (2008), ${ }^{4}$ which speaks of a commitment to help people stay healthy through commissioning of wellbeing and prevention services.

The UK Faculty of Sport and Exercise Medicine is the governing body for the specialty and its objectives include:

- To promote for the public benefit the advancement of education and knowledge in the field of SEM.
- Establish a career pathway in SEM.

- To develop and maintain for the public benefit the good practice of SEM by ensuring the highest professional standards of competence and clinical integrity.

- To act as the authoritative body for the purposes of consultation in matters of professional, educational or public interest concerning SEM.

- To advance the science of SEM.

- To establish the standards and competences required for entry onto the Specialist Register in SEM.

There are currently approximately 550 fellows and members of the faculty (www.fsem.co.uk).

Sport and exercise medicine is a 'broad church' specialty consisting of doctors who, as part of multidisciplinary teams, provide:

- a holistic approach to addressing medical conditions and injuries in those who are physically active, exercise and engage in sport;

- prevention of injuries and illness by providing advice on the safe use of physical activity in the treatment and prevention of illness; and

- promotion of health and wellness through the increased use and uptake of exercise and physical activity.

It provides care and advice for all people and patients irrespective of age, sex or ability.

As well as being a speciality that seeks to promote health and prevent disease or injury it has a major role to play in the treatment and rehabilitation of injuries. Each year in the UK there are an estimated 29 million new or recurrent injuries resulting from participation in organized sport or physical activity. Ten million of these are substantive resulting in patients being unable to work or continue their usual activities. The cost to the NHS of treating these injuries is estimated to be 590 million pounds per annum. For each hospital admission for a sport or recreational injury there are 11 emergency department and 12 general practitioner visits.

Higher Specialty Training in SEM commences after four years of basic postgraduate training (FY1 and 2, ST1 and 2) and is a further four years in duration. In the UK, it is essentially a 'medical' specialty and trainees can enter specialty training at ST3 from one of three routes, namely core medical training (CMT), acute care common stem (ACCS) or general practice. Achieving ST2 competencies in one of these pathways is an essential requirement for entry to the SEM training program. In addition potential trainees are expected to be able to show a commitment to the specialty, for example through membership of BASEM and previous attendance at relevant courses and conferences. To date competition for places on training schemes has been keen 
and successful applicants have often had substantial experience with sports teams, or have held a postgraduate qualification such as a taught university diploma or masters degree.

The 'broad church' ethos is reflected in the specialty curriculum which has been developed to allow trainees to gain appropriate experience and skills in a range of related disciplines, including public health, general practice, general medicine (including cardiology and rheumatology), orthopaedics and emergency medicine. In addition to this at least eighteen months of the four-year program will take place in a variety of SEM environments, both within the NHS and private sector, encompassing supervized exposure to both elite and recreational athlete populations, including disability sport. Trainees will have the opportunity to work as part of multidisciplinary teams providing care to a range of individual and team sports, including mass participation events such as marathons. Out of program opportunities may exist for trainees to complete part of their training overseas or to gain additional supervized experience traveling as part of a medical support team to international sporting events. Applications for all such activities will have to gain prospective approval from the postgraduate dean for the region and from the Specialist Advisory Committee and Postgraduate Medical Education and Training Board (PMETB).

The specialty curriculum currently contains fifteen separate modules covering all aspects of clinical SEM practice, with each module containing a defined set of knowledge, experience and skills that a trainee will be expected to achieve. Central to the program is an in depth understanding of the scientific principles of exercise physiology, anatomy and nutrition which underpin the diagnosis and treatment of exercise related medical problems and injury, as well as the therapeutic use of exercise in disease management and prevention. In common with all medical specialties in the UK, the SEM curriculum has recently undergone a comprehensive review and the new training syllabus will come into effect in 2010 (see www.jrcptb.org.uk for further information).

The objective of the training program is to produce a doctor who will be capable of providing leadership in the promotion and adoption of physically active lifestyles for both the prevention and management of chronic ill health, and in the treatment and prevention of exercise related injuries to all sectors of the population, from the 'weekend warrior' to the professional athlete. Trainees are encouraged to contribute to the emerging knowledge base of the specialty by undertaking research and by participating in regular audit. Trainees are expected to develop the leadership and management skills appropriate to a consultant working within the NHS and to become involved in teaching at both undergraduate and postgraduate levels. The UK training program differs substantially from that of other countries by its emphasis on the role of exercise as a driver for health and in the management of chronic disease.

Progression through the training program will be monitored using a range of validated workplace based assessments developed by the Royal College of Physicians of London (MiniCex, DOPS, CbD, MSF etc) and satisfactory annual review meetings, confirming the attainment of the curriculum competencies appropriate to the registrar's stage of training. Successful completion of the UK Diploma in Sport and Exercise Medicine is mandatory by the end of ST4 to allow progression to ST5. The diploma is run by the examination committee of the Faculty of Sport and Exercise Medicine FSEM (UK) and has recently undergone a significant review to ensure alignment to modern assessment theory and methodology.

There are currently 33 registrars in training posts in SEM across postgraduate deaneries in England, Scotland, Wales, and Northern Ireland. Several of the initial tranche of doctors who commenced training in 2007 have successfully gained inclusion on the Specialist Register via the CESR/Article 14 pathway (see www.pmetb.org. uk for further information on this process). The rapid expansion of training that has been supported by both the Department of Health and Regional Postgraduate Deans is encouraging and reflects a confidence and understanding of the positive impact that SEM doctors can play in a future health service. The major challenge facing the specialty is to create a demand for SEM Consultants within the NHS. ${ }^{5}$ Considerable progress is being made on this front and there is optimism that 2010 will herald a breakthrough in the journey to seeing SEM fully integrated within the National Health Service of the UK.

The journey to the recognition of SEM as a distinct medical specialty in the UK has been long and often tortuous. We owe a debt of gratitude to those pioneering colleagues who had the foresight to realize that exercise is essential to health and the determination to gather the scientific evidence upon which our specialty is founded. Sport and exercise medicine specialists offer a truly novel approach to healthcare delivery based on the wellness rather than the sickness model and would appear ideally placed to contribute positively to the fight against the myriad problems associated with our physically inactive lifestyles. 


\section{Disclosure}

Professor Cullen was a member of The UK Sport/DCMS/DH Sport and Exercise Medicine Workgroup.

\section{Acknowledgments}

The author acknowledges the assistance provided by Professor Mark Batt (President FSEM) and Professor Charles Galasko (immediate past President FSEM) in the preparation of this manuscript.

\section{References}

1. Department for Culture, Media and Sport, Prime Minister's Strategy Unit. Game Plan - a strategy for delivering the government's sport and physical activity objectives. London: Cabinet Office; 2002.

2. Department of Health. Choosing Health - making healthier choices easier. London: Department of Health; 2004.

3. Department of Health. Be Active, Be Healthy: a plan for getting the nation moving. London: Department of Health; 2009.

4. National Health Service (NHS). High Quality Care for All - NHS next stage review. Final report; 2008;Cm 7432.

5. Cullen M. Crossroads or threshold? Sport and exercise medicine as a specialty in the UK. BJSM. 2009;43(14):1083-1084.

\section{Publish your work in this journal}

Open Access Journal of Sports Medicine is an international, peer-reviewed, open access journal publishing original research, reports, reviews and commentaries on all areas of sports medicine. The manuscript management system is completely online and includes a very quick and fair peer-review system.
Visit http://www.dovepress.com/testimonials.php to read real quotes from published authors. 